devoted to this order. In dealing with the Culicidæ (mosquitoes), Colonel Alcock's good sense is shown by his retention for this much "classified" family of the original subdivision into the two subfamilies Corethrinæ and Culicinæ; it should be nuted, however, that, in deference to the principle that designations of groups of equal value should have similar terminations, the author has since adopted for the four groups into which tne Culicinæ are divided a nomenclature somewhat different from that given by him in this book. Another detail worthy of mention is the treatment of the Anopheline mosquitoes as belonging to the single genus Anopheles, instead of to more than twenty so-called genera; whatever genus-makers may say, this course is undoubtedly convenient for the medical officer, besides being for the most part in strict accordance with the principles of true taxonomy.

Exigencies of space forbid us from referring at length to other classes and orders, and it must therefore suffice to state that while groups admittedly noxious, such as the fleas, lice, bugs, ticks, and scorpions, receive adequate consideration, the reader who wishes to learn something of friendly or neutral Arthropods will not refer to this volume in vain. Derivations and explanations of generic and other names are a useful feature of the book, which is copiously illustrated with clearly-drawn figures, and is distinguished wherever possible by a literary touch too often conspicuously absent from zoological text-books. By the compilation and publication of this volume Colonel Alcock has placed students of tropical medicine under a debt of gratitude which they will not find it easy to repay, and every medical and sanitary officer in the tropics may confidently be recommended to add the book to his necessarily limited library.

E. E. A.

\section{TRANSFORMER DESIGN.}

The Design of Static Transformers. By H. M. Hobart. Pp. xv+ I74. (London: Constable \& Co., Ltd., I9II.) Price $6 s$. net.

\footnotetext{
A BOOK from the pen of Mr. Hobart invariably A commands respectful attention and, we may add, is invariably pleasant reading. The volume before us is no exception, and moreover presents the results of Mr. Hobart's wide experience-that is to say, within the range of subjects taken up in this volume-with great conciseness. Perhaps one of the most valuable parts of the book is that labelled "Introductory," which occupies the first eleven pages. The last nine of these pages constitute a survey of the development of the "static" transformer, and the survey is, to the engineer
} NO. 2228, VOL. 89] whose recollections carry him back over the period covered, freshingly interesting, and to the student it is full of instruction. Beginning with reference to the pioneer investigations of other workers, to which student and engineer alike are exhorted to give heed, Mr. Hobart culls from his own past experience and recollections incidents which illustrate in the most striking way what is really a typical sample of the commercial development of a scientific piece of apparatus. No better example than Mr. Hobart's experience with wattmeters could be given to impress students with the way in which difficulties should be met and with the way in which, when so met, they lead invariably to progress. We cannot leave this excellent part of the book, all too brief as it is, without expressing hearty approval of the statement that "the subject of transformer design cannot be covered by the enunciation of rules, formulæ and constants, but that the designing of a transformer . . . will for many years continue to afford ample scope for careful thought and work."

There is some inconsistency in the remark on page 16 that "it is rare to find a graduate who has the remotest idea of how to proceed in designing a commercial transformer" with the statement a few lines below that "there are very many practical points based on long experience" and "it is particularly true of transformer designing that past experience goes a long way." Mr. Hobart, however, puts at the disposal of the inexperienced graduate a digest of his own lengthy and valuable experience.

Of that part of the book which constitutes the main reason for its existence, in our opinion the chapter on "The Design of the Windings and Insulation" is the weakest, and not only so, but is distinctly weak. The whole matter is dismissed in $5^{\frac{1}{2}}$ pages, of which one whole page and practically three others are occupied by illustrations. The method of arriving at the dimensions of the secondary conductor is entirely skipped, and no reference whatever is made to any requirements in the way of insulation beyond that made in the vaguest of terms in the text and the details stated in bare terms upon the drawings. To go to the other extreme, we find in the chapter on the "Heating of Transformers " the most excellent treatment, the subject being dealt with both broadly and in detail in the most valuable manner. The chapter on "Cases and Tanks" is also one which will fill a very decided gap in the literature relating to transformers.

We cannot dismiss reference to this work, so excellent in itself, without deploring the occurrence of grammatical and similar inaccuracies and inconsistencies. 